\title{
Educação de surdos e deficientes auditivos: uma análise dos indicadores sociais
}

\author{
Raquel Elizabeth Saes Quiles*
}

\section{Resumo}

Este trabalho apresenta de forma diagnóstica um panorama da educação de surdos e deficientes auditivos no Brasil, região Centro-Oeste e estado de Mato Grosso do Sul, no período de 2007 a 2010. Seu objetivo principal centrou-se no mapeamento das matrículas e modalidades de atendimento em que estão inseridos esses alunos. Para tanto, a fonte de dados do estudo foram os microdados do Instituto Nacional de Estudos Pedagógicos Anísio Teixeira (INEP), divulgados nos censos escolares. Buscou-se analisar os dados considerando as propostas educacionais evidenciadas nas políticas públicas em Educação Especial, em discussão no período do estudo, aprofundando, portanto, questionamentos relacionados à educação inclusiva. Os resultados encontrados demonstram que houve um crescimento no número de matrículas tanto de surdos quanto de deficientes auditivos nas três esferas - nacional, regional e estadual - e que a grande maioria desses alunos encontram-se matriculados no ensino regular, evidenciando um enfraquecimento da modalidade de educação especial durante os últimos anos. Conclui-se que o aumento de matrículas no ensino regular provavelmente responde à imposição das políticas educacionais brasileiras no período do estudo, que orientam à inserção de todos os alunos nessa modalidade de ensino. Porém, questiona-se as condiçóes de inclusão dos alunos surdos e deficientes auditivos e, ainda, se esta seria a melhor opçáo de ensino especialmente para os surdos, que têm lutado por uma escola bilíngue, que respeite suas singularidades linguísticas, o que não necessariamente significa a escola inclusiva pensada nos moldes do atual governo brasileiro.

Palavras-chave: Surdez; Deficiência auditiva; Indicadores sociais; Educação inclusiva.

\footnotetext{
* Professora da Universidade Federal de Mato Grosso do Sul. Campo Grande, Mato Grosso do Sul, Brasil.
} 


\section{Education for the deaf and the hearing impaired: an analysis of social indicators}

\section{Abstract}

This paper presents, in a diagnostic way, a scenario of the education for the deaf and the hearing impaired in Brazil, the Midwest-region and the state of Mato Grosso do Sul, from 2007 to 2010. It aimed at the mapping of the enrollments and terms of service in which these students are inserted. For doing so, the study was based on the microdata from National Institute of Pedagogical Studies Anísio Teixeira (INEP), which is disclosed on the school census. It focused on analyzing the data considering the educational proposals focused on public policies for Special Education under discussion during the research period, thus, deepening the questions concerning inclusive education. Results have shown a growing number of enrollments of hearing impaired and deaf students in the national, regional and state spheres and that most students are enrolled in regular education, which points out the weakening of special education for these students along the last years. The conclusion is that this growing number of enrollments in regular education is probably a response to the imposition of brazilian educational policies during the research period, which guide the insertion of all students in this type of education. However, not only the conditions for including the deaf and hearing impaired students are questioned, but also the fact if this one would the best option, especially for the deaf, who have struggled for a bilingual school, which may respect their linguistic singularities, and this does not necessarily means the inclusive school molded by the current Brazilian government.

Keywords: Deafness; Hearing disability; Social indicators; Inclusive education.

\section{Introdução}

Este trabalho apresenta parte dos resultados de uma pesquisa que teve a intenção de analisar a situação da educação de surdos no país, na região Centro-Oeste e no estado de Mato Grosso do Sul, a partir da análise dos microdados do Instituto Nacional de Estudos Pedagógicos Anísio Teixeira (INEP), divulgados nos censos escolares, no período de 2007 a 2010.

Este tipo de pesquisa se justifica, principalmente, pela possibilidade de verificar como tem ocorrido a inserção de surdos na Educação Básica nos últimos anos, considerando a opção do governo brasileiro, especialmente a partir de $2008,{ }^{1}$ pela efetivação da educação inclusiva, proposta respaldada pela defesa da educação para todos, sem distinção, no ensino regular.

Nesse contexto, a educação de surdos ${ }^{2}$ se coloca como um campo de estudos em destaque, principalmente porque a construção dessa escola inclusiva para um grupo de pessoas que possui uma língua diferenciada, não parece ser uma tarefa simples. Assim, estudar a surdez no contexto educacional brasileiro atual significa, essencialmente, estudar a proposta de educação inclusiva e, nesse sentido, indagar sobre os desafios e perspectivas advindos dessa proposta. 
Dessa forma, surgem as seguintes questóes que serviram como preocupaçôes do estudo: com o advento da inclusão, qual a realidade evidenciada no país no que se refere às matrículas dos alunos surdos no sistema educacional de ensino? Houve um crescimento dessas matrículas a partir das políticas públicas consideradas inclusivas? Em qual modalidade de ensino?

Assim, a pesquisa objetivou verificar a educação de surdos nessas três esferas - nacional, regional e estadual - através da análise dos indicadores sociais brasileiros, contemplando as seguintes variáveis: índice das matrículas e modalidades de atendimento. Porém, cabe ressaltar que no momento do levantamento dos dados, detectou-se que o INEP apresenta duas possibilidades de categorização direcionadas ao público-alvo deste estudo: alunos com surdez e alunos com deficiência auditiva. Constatou-se, por meio de consulta aos Manuais do Usuário do INEP (2007-2008 e 2009-2010), que, no momento do preenchimento das informaçóes referentes a cada aluno, deve-se informar se o mesmo possui ou não deficiência, transtorno global do desenvolvimento ou altas habilidades/superdotação (com base em laudo médico). Ao informar que sim, a próxima questão relaciona-se ao tipo de deficiência. É neste momento que ocorre a divisão entre alunos com surdez e alunos com deficiência auditiva. Acredita-se que esta diferenciação visa traçar o perfil do público-alvo atendido pela escola, sugerindo, portanto, que, no entendimento do INEP, aluno com surdez não é sinônimo de aluno com deficiência auditiva, apesar dos dois grupos serem compreendidos como alunos com deficiência. ${ }^{3}$

Esse dado redirecionou a perspectiva do estudo, que inicialmente se propunha a pensar apenas a educação de surdos. Assim, os resultados evidenciados refletem também sobre a educação de deficientes auditivos.

\section{Metodologia}

A pesquisa foi realizada em dois momentos. O primeiro voltou-se para o levantamento dos dados, com base nas variáveis escolhidas, a partir dos microdados da Educação Básica, disponibilizados pelo INEP, no período de 2007 a 2010, focando o Brasil, a regiáo Centro-Oeste e o estado de Mato Grosso do Sul. O segundo momento focou na análise dos dados encontrados. Para tanto, ponderou-se os conceitos e discussôes relacionados à educação inclusiva e educação de surdos e deficientes auditivos, na tentativa de realizar uma análise qualitativa dos dados, problematizando os desafios e perspectivas. Acredita-se que esse cuidado metodológico possibilitou uma discussão mais crítica da realidade compartilhada pelo Ministério da Educação (MEC).

As duas variáveis escolhidas para mediar a apresentação dos resultados foram as matrículas de surdos e deficientes auditivos, que demonstram dados relacionados ao acesso à educação; e as modalidades de ensino em que são atendidos, que indicam as perspectivas relacionadas às escolas e classes especiais, e à inserção no ensino regular ou na educação de jovens e adultos. ${ }^{4}$

Cabe ressaltar que os dados foram extraídos dos microdados do censo escolar por meio do Programa Statistical Package for the Social Sciences (SPSS), um software 
que possibilita realizar cálculos estatísticos complexos, permitindo uma apresentação e interpretação sucinta dos resultados obtidos. As informaçôes referentes a cada grupo de alunos (surdos e deficientes auditivos) foram categorizadas separadamente, considerando que as informaçóes desses dois grupos estáo disponíveis desta forma nos microdados.

\section{Resultados}

Por meio dos dados do INEP, foi possível visualizar o crescimento ou não de atendimentos direcionados a alunos com necessidades educacionais especiais. ${ }^{5}$ Essa informação foi importante para a pesquisa realizada por servir como base para a análise do percentual de surdos e deficientes auditivos matriculados no bojo desse grupo de alunos.

Um destaque importante refere-se à forma como o INEP conceitua a pessoa com surdez e com deficiência auditiva, evidenciada nas orientaçóes de preenchimento do censo escolar. Segundo essas orientaçôes, considera-se surdo aquele que tem "perda auditiva acima de $71 \mathrm{~dB}$, aferida por audiograma nas frequências de $500 \mathrm{~Hz}$, $1000 \mathrm{~Hz}, 2000 \mathrm{~Hz}$ e $3000 \mathrm{~Hz}$. O aluno com essa surdez, em geral, utiliza a Língua Brasileira de Sinais (Libras)" (BRASIL, 2010, p. 34). Já a deficiência auditiva refere-se à:

[...] perda bilateral, parcial ou total, de $41 \mathrm{~dB}$ até $70 \mathrm{~dB}$, aferida por audiograma nas frequências de $500 \mathrm{~Hz}, 1000 \mathrm{~Hz}, 2000 \mathrm{~Hz}$ e $3000 \mathrm{~Hz}$. O aluno que utiliza o Aparelho de Amplificaçáo Sonora Individual - AASI (prótese auditiva) pode, ou náo, processar informaçóes linguísticas pela audição e, consequentemente, tornarse capaz de desenvolver a linguagem oral, mediante atendimento fonoaudiológico e educacional. (BRASIL, 2010, p. 33).

Percebe-se que nenhum dos dois conceitos está em consonância com a definição trazida pelo Decreto n. 5.626/2005, ${ }^{6}$ que concebe a pessoa com surdez como aquela que "por ter perda auditiva, compreende e interage com o mundo por meio de experiências visuais, manifestando sua cultura principalmente pelo uso da Língua Brasileira de Sinais - Libras" (art. $2^{\circ}$ ). Por sua vez, a deficiência auditiva é entendida como "a perda bilateral, parcial ou total, de quarenta e um decibéis $(\mathrm{dB})$ ou mais, aferida por audiograma nas frequências de $500 \mathrm{~Hz}, 1.000 \mathrm{~Hz}, 2.000 \mathrm{~Hz}$ e $3.000 \mathrm{~Hz}$ " (parágrafo único).

O que se pode perceber no conceito de surdez, trazido pelo INEP é que se trata de uma definição determinada pelo aspecto biológico, focada na perda auditiva, enquanto que o conceito evidenciado pelo Decreto n. 5.626/2005 se volta para uma especificidade fundamental da pessoa surda, qual seja, a utilização de uma outra língua que, por sua vez, conduz a uma forma diferenciada de entender o mundo, a partir das experiências visuais.

Quanto ao conceito de deficiência auditiva, apesar do texto do INEP estar parecido com o do Decreto n. 5.626/2005, o Decreto não delimita até quantos decibéis de perda se considera deficiência auditiva. Além disso, o texto legal não especifica so- 
bre a aquisição ou não da linguagem oral, até mesmo porque esta não é a perspectiva desse documento, que defende o reconhecimento linguístico através da Libras.

Destacada essa contradição, apresenta-se abaixo uma tabela que demonstra o crescimento das matrículas de surdos e deficientes auditivos (D.A.) no país em comparação com o número de alunos com necessidades educacionais especiais (NEE's) matriculados, no período de 2007 a 2010.

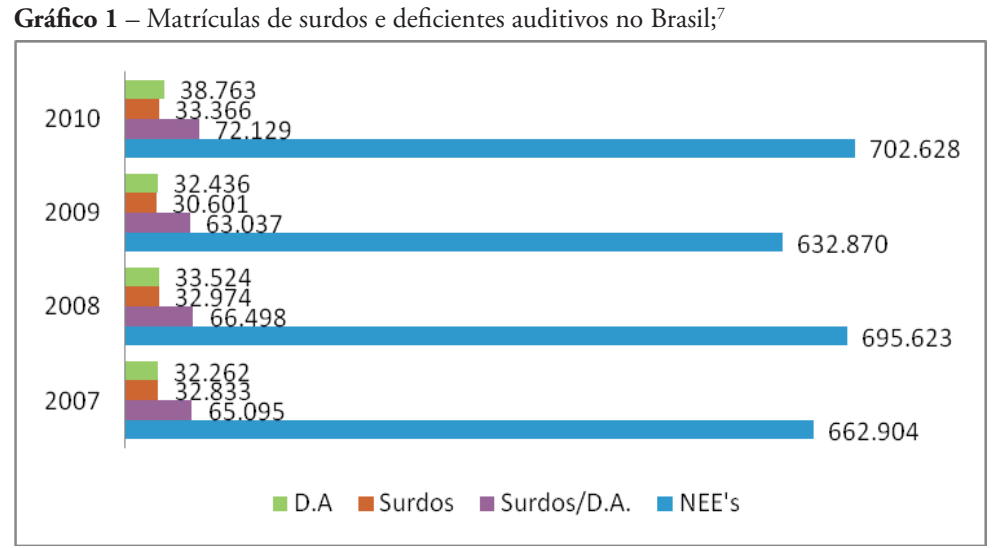

Fonte: MEC/INEP. Censo escolar da Educação Básica: microdados, 2007 a 2010

Uma primeira observação que se pode fazer analisando esses dados é que a matrícula de surdos e deficientes auditivos juntos significa, em média, 10\% do número de alunos com NEE's matriculados. Além disso, o número de surdos e deficientes auditivos acompanha o crescimento e queda de matrículas dos alunos com NEE's. Ou seja, percebe-se uma queda de matrículas de 2008 para 2009 e um salto quantitativo no ano de 2010, tanto na matrícula dos alunos com NEE's quanto dos alunos com surdez e com deficiência auditiva.

Acredita-se que esse aumento de matrículas no ano de 2010 seja uma consequência da implementação da Política Nacional de Educação Especial na perspectiva da Educaçâao Inclusiva, de 2008, pois, apesar de em 2009 ter ocorrido uma queda de matrículas, entende-se que a implementação de uma política não é imediata, mas gradativa.

Outra consideração importante refere-se ao fato de haver mais deficientes auditivos matriculados do que surdos a partir do ano de 2008, o que leva ao seguinte questionamento: será que, com o passar dos anos, houve uma clareza maior da distinção entre esses dois grupos de alunos? Hipotetizando que sim, isso explicaria o fato de haver uma diminuição na matrícula de surdos e um crescimento na matrícula de deficientes auditivos, considerando que a partir do próprio conceito de surdez do INEP, surdo é aquele que tem uma perda auditiva maior, acima de 71 decibéis, o que inclui, obviamente, um grupo menor de alunos. Porém, não se pode afirmar que todos os alunos considerados surdos matriculados utilizam a Libras como meio de comunicação. Ao refletir sobre o conceito de surdez, apresentado pelo Decreto n. 5.626/2005, fica evidente que o uso da Libras está intimamente ligado com a concepção de surdez, 
o que não parece estar claro no conceito trazido pelo INEP. Dessa forma, os dados trazidos pelos censos escolares não são esclarecedores sobre a real condição linguística dos alunos matriculados.

Ao analisar os dados da região Centro-Oeste, percebe-se uma diferença significativa entre o número de surdos e deficientes auditivos matriculados, como se pode observar a seguir.

Gráfico 2 - Matrículas de surdos e deficientes auditivos no Centro-Oeste

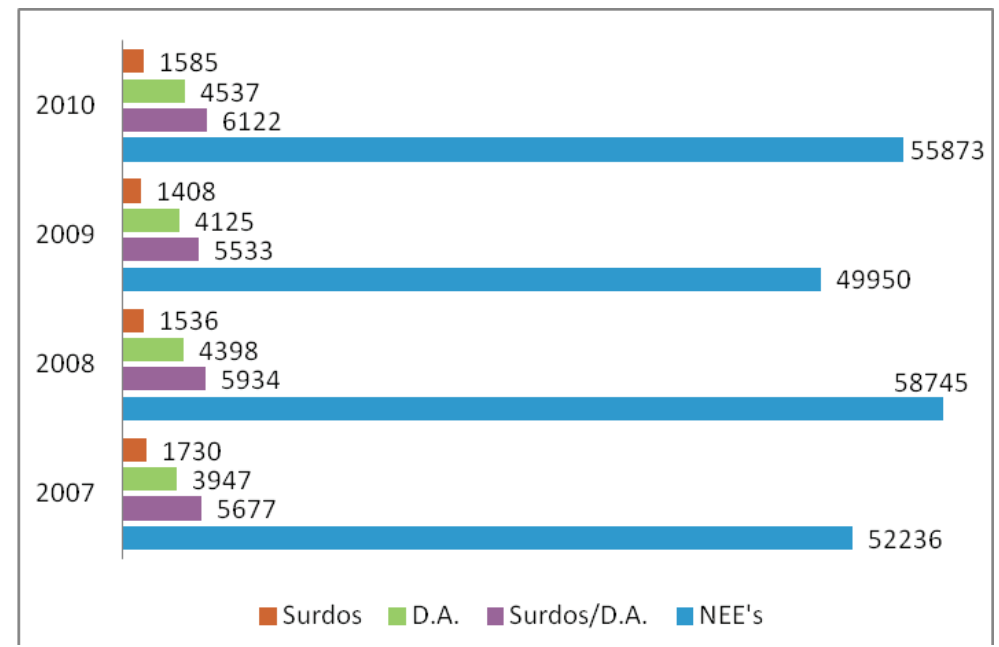

Fonte: MEC/INEP. Censo escolar da Educação Básica: microdados, 2007 a 2010

Apesar de, no Brasil, também haver mais deficientes auditivos do que surdos matriculados, na região Centro-Oeste o número de deficientes auditivos é quase o triplo, a partir de 2008, em comparaçáo com o número de surdos matriculados. Além disso, o número de surdos matriculados em 2010 é menor que o número de surdos matriculados em 2007, o que não acontece no país.

Com relação à queda de matrículas no cenário nacional, no ano de 2009, o mesmo acontece com a região Centro-Oeste. Tendo o número de alunos com NEE's como parâmetro, a soma do número de surdos e deficientes auditivos matriculados também acompanha o que se evidencia no país, mantendo-se uma média de 10\% do número de alunos com NEE's em todos os anos analisados. ${ }^{8}$

Ao verificar a situação do estado de Mato Grosso do Sul (MS), percebe-se algumas mudanças em relação ao cenário nacional, como se pode observar no próximo gráfico. 
Gráfico 3 - Matrículas de surdos e deficientes auditivos em MS:

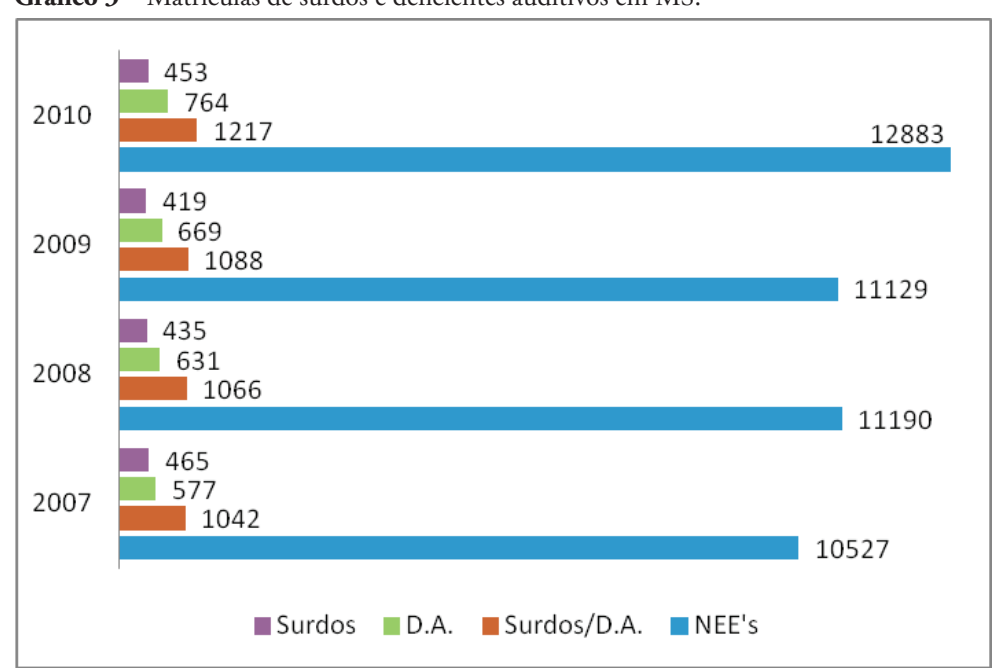

Fonte: MEC/INEP. Censo escolar da Educação Básica: microdados, 2007 a 2010

Interessante perceber que em MS, apesar de também haver uma queda de matrículas no ano de 2009, a mesma não é táo significativa como se observa no Brasil e na regiấo Centro-Oeste. O número de surdos matriculados cai gradativamente de 2007 a 2009, aumentando apenas em 2010, o que é natural já que há um forte crescimento de matrículas nesse ano em todo o país. Já em relação à deficiência auditiva há um crescimento linear de matrículas no decorrer do período analisado, não havendo queda nem no ano de 2009, como acontece no país e na região Centro-Oeste. Somando a matrícula de surdos e deficientes auditivos em cada ano, a média de $10 \%$ em relação ao número de alunos com NEE's matriculados permanece. ${ }^{9}$

Ao ponderar o cenário nacional, regional e estadual fica a dúvida sobre o porquê da queda de matrículas no ano de 2009 nas três esferas. Outra indagação premente refere-se ao número de alunos deficientes auditivos ser significativamente maior que o número de surdos matriculados, pois, como já ponderado, não é possível afirmar que isso ocorra devido a uma clareza conceitual das escolas no momento do preenchimento do censo escolar, até porque isso, provavelmente, significaria um número ainda mais reduzido de surdos matriculados do que o evidenciado. ${ }^{10}$ Assim, permanece a indagação sobre a situação linguística dos alunos entendidos como surdos e/ou deficientes auditivos.

Uma outra análise dos microdados na pesquisa se deu a partir das modalidades de atendimento, ${ }^{11}$ que se dividem em três possibilidades: ensino regular, educação especial e educaçáo de jovens e adultos (EJA). Em âmbito nacional, encontra-se o seguinte panorama: 
Tabela 1 - Matrículas de surdos e deficientes auditivos por modalidade no Brasil ${ }^{12}$ :

\begin{tabular}{|l|l|l|l|l|l|l|l|}
\hline & \multicolumn{2}{|l|}{ Ensino Regular } & \multicolumn{2}{l|}{ Educação Especial } & \multicolumn{2}{l|}{ EJA } & \multirow{2}{*}{ Total } \\
\cline { 2 - 7 } & Surdos & D. A. & Surdos & D. A. & Surdos & D. A. & \\
\hline 2010 & 19.061 & 28.901 & 11.123 & 6.944 & 3.182 & 2.918 & 72.129 \\
\hline 2009 & 15.427 & 21.945 & 12.441 & 8.118 & 2.733 & 2.373 & 63.037 \\
\hline 2008 & 15.335 & 19.981 & 14.917 & 11.134 & 2.722 & 2.409 & 66.498 \\
\hline 2007 & 13.926 & 16.570 & 16.351 & 13.672 & 2.556 & 2.020 & 65.095 \\
\hline
\end{tabular}

Fonte: MEC/INEP. Censo escolar da Educação Básica: microdados, 2007 a 2010

Pode-se perceber a constante queda de matrículas tanto de surdos quanto de deficientes auditivos na modalidade de educação especial e um crescimento, também constante, de matrículas no ensino regular durante o período analisado.

Especialmente, é interessante notar o número de alunos com deficiência auditiva matriculados na modalidade de educaçáo especial, que se apresenta bem menor que o número de surdos matriculados nessa mesma modalidade. Como as matrículas de deficientes auditivos sempre somaram um número maior de alunos no período analisado, em comparação com o número de surdos, ${ }^{13}$ acreditava-se que, em todas as modalidades de atendimento, isso iria acontecer. Porém, a tabela acima mostra que provavelmente os alunos com deficiência auditiva estiveram, em sua grande maioria, matriculados no ensino regular, pois, mesmo com a queda de matrículas na modalidade de educação especial acontecendo gradualmente, a matrícula de deficientes auditivos no ensino regular se mostra sempre maior. No caso da surdez, o movimento de transição de uma modalidade (educação especial) para a outra (ensino regular) é gradual.

Essa constatação não se evidencia da mesma forma na regiáo Centro-Oeste, como se pode observar a seguir:

Tabela 2 - Matrículas de surdos e deficientes auditivos por modalidade no Centro-Oeste:

\begin{tabular}{|l|l|l|l|l|l|l|l|}
\hline & \multicolumn{2}{|l|}{ Ensino Regular } & \multicolumn{2}{l|}{ Educação Especial } & \multicolumn{2}{l}{ EJA } & \multirow{2}{*}{ Total } \\
\cline { 2 - 7 } & Surdos & D. A. & Surdos & D. A. & Surdos & D. A. & \\
\hline 2010 & 1.031 & 3.619 & 386 & 627 & 168 & 291 & 6.122 \\
\hline 2009 & 894 & 3.299 & 350 & 559 & 164 & 267 & 5.533 \\
\hline 2008 & 887 & 2.989 & 517 & 1.131 & 132 & 278 & 5.934 \\
\hline 2007 & 851 & 2.357 & 724 & 1.413 & 155 & 177 & 5.677 \\
\hline
\end{tabular}

Fonte: MEC/INEP. Censo escolar da Educação Básica: microdados, 2007 a 2010

O que esta tabela evidencia é que a região Centro-Oeste acompanha o cenário nacional em relação à queda de matrículas na modalidade de educação especial e o crescimento das mesmas na modalidade do ensino regular. Porém, tanto os alunos com deficiência auditiva quanto os surdos estáo, durante todo o período analisado, mais concentrados no ensino regular. 
Por fim, no estado de Mato Grosso do Sul, encontra-se a mesma situação evidenciada no país, como se pode perceber na tabela a seguir:

Tabela 3 - Matrículas de surdos e deficientes auditivos por modalidade em MS:

\begin{tabular}{|l|l|l|l|l|l|l|l|}
\hline \multirow{2}{*}{} & \multicolumn{3}{|l|}{ Ensino Regular } & \multicolumn{3}{l|}{ Educação Especial } & \multicolumn{2}{l|}{ EJA } & \multirow{2}{*}{ Total } \\
\cline { 2 - 7 } & Surdos & D. A. & Surdos & D. A. & Surdos & D. A. & \\
\hline 2010 & 264 & 607 & 114 & 64 & 75 & 93 & 1.217 \\
\hline 2009 & 214 & 523 & 117 & 50 & 88 & 96 & 1.088 \\
\hline 2008 & 213 & 497 & 143 & 45 & 79 & 89 & 1.066 \\
\hline 2007 & 172 & 442 & 224 & 70 & 69 & 65 & 1.042 \\
\hline
\end{tabular}

Fonte: MEC/INEP. Censo escolar da Educação Básica: microdados, 2007 a 2010

Ou seja, há um crescimento de matrículas no ensino regular durante o período analisado e, consequentemente, uma queda nas matrículas na educação especial. Porém, como no Brasil, o número de deficientes auditivos é sempre maior na modalidade de ensino regular, enquanto que no caso da surdez há uma mudança gradual, pois, em 2007, há mais surdos matriculados na educação especial do que no ensino regular e, em 2010, já se evidencia o contrário.

$\mathrm{O}$ que se considera mais marcante ao analisar os dados referentes às modalidades de atendimento é que a educação especial foi perdendo forças enquanto espaço de escolarização com o passar dos anos e, consequentemente, o ensino regular se fortalece como lugar de direito de todos os alunos, dentre eles, os surdos e deficientes auditivos. Acredita-se que as razões que explicam esse fenômeno estão relacionadas com as políticas públicas em educação especial evidenciadas no período analisado. Isto é, dizem respeito à implementação no país do que comumente tem se chamado de educação inclusiva. ${ }^{14}$

Para alguns autores, como Mendes (2006), a inclusão significa uma ruptura do paradigma educacional tradicional e a construção de uma nova proposta de ensino que atenda a todos os alunos com qualidade. Outros pesquisadores, relacionando as políticas públicas educacionais com as relaçôes de mercado delas provenientes, como Ferreira e Ferreira (1994), têm entendido a inclusão como uma política de barateamento de custos e uma estratégia para se eliminar os serviços da educação especial. Há ainda autores, como Lancillotti (2003), que têm asseverado que a inclusão é um conceito amplamente ideológico, pois, em um país de imensa exclusão social, fala-se de incluir a todos. ${ }^{15}$

De fato, é evidente que a inclusão se coloca como uma bandeira de luta nos discursos e propostas do Ministério da Educação, traduzindo-se, nos documentos que compóem a política educacional na atualidade, na inserçâoo (matrícula) de todos os alunos no ensino regular, como um direito público subjetivo. Contudo, cabe questionar o que isso tem significado na qualidade do processo educacional dos alunos com surdez e deficiência auditiva, isto é, será que a inclusão no ensino regular tem sido o caminho mais eficaz na garantia da escolarização desses alunos ou o crescimento das matrículas no ensino regular desse alunado responde a uma política educacio- 
nal amplamente disseminada que, muitas vezes, só tem garantido o acesso à educação sem uma real proposta de ensino que assegure a permanência e sucesso acadêmico?

As políticas públicas educacionais, como políticas sociais, significam o Estado em ação e, segundo Höfling (2001):

As ações empreendidas pelo Estado não se implementam automaticamente, têm movimento, têm contradiçóes e podem gerar resultados diferentes dos esperados. Especialmente por se voltar para e dizer respeito a grupos diferentes, o impacto das políticas sociais implementadas pelo Estado capitalista sofrem o efeito de interesses diferentes expressos nas relaçóes sociais de poder. (HÖFLING, 2001, p. 35).

Considerando, portanto, que os processos de definição de políticas públicas refletem conflitos de interesses, faz-se necessário questionar sobre as reais necessidades educacionais dos alunos com surdez e com deficiência auditiva. Nesse sentido, não se pode ignorar, no processo de construção das políticas públicas, os anseios da sociedade civil, pois como salienta Kassar (2001), "dar oportunidades iguais nem sempre significa dispensar o mesmo tratamento. A escola deve ter por objetivo possibilitar o mesmo acesso, o que não significa oferecer sempre os mesmos meios" (p. 61).

\section{Concluindo...}

Como evidenciado na apresentaçáo dos resultados, provenientes da análise dos microdados do INEP, no período de 2007 a 2010, no que se refere à matrícula e modalidades de atendimento dos alunos com surdez e deficiência auditiva, o cenário que se evidencia é o de crescimento da inserçáo desse alunado no âmbito educacional, especialmente na modalidade de ensino regular. Essa realidade está presente tanto no Brasil quanto na região Centro-Oeste e no estado de Mato Grosso do Sul.

A crescente inserção de surdos e deficientes auditivos no ensino regular parece ser algo positivo, pois significa que houve uma ampliação dos serviços educacionais a esse grupo de alunos. Porém, a preocupaçáo suscitada deste estudo refere-se às condiçôes dessa inclusão. Os dados do INEP não são esclarecedores quanto aos serviços que têm sido colocados ou não à disposição desse alunado, como, por exemplo, o serviço do tradutor e intérprete de Libras no caso dos alunos com surdez.

Contudo, para além desta preocupação, outra ainda se coloca como preponderante. Refere-se à situaçáo de inclusáo em si, especialmente quando se trata dos alunos com surdez. Os surdos no Brasil têm se organizado socialmente, principalmente após a promulgaçáo da Lei n. 10.436/2002, na busca pelo direito linguístico. Assim, o questionamento que se faz é: será que o processo inclusivo, evidenciado especialmente pela inserção no ensino regular, tem garantido a efetivação e uso da Libras como língua de instruçáo dos alunos com surdez?

A reivindicação dos surdos no cenário nacional parece ser por uma escola bilíngue, o que não significa, necessariamente, uma escola inclusiva, pelo menos não na perspectiva do MEC. ${ }^{16}$ Conforme o Decreto n. 5.626/2005, são denominadas 
escolas ou classes de educação bilíngue "aquelas em que a Libras e a modalidade escrita da Língua Portuguesa sejam línguas de instrução utilizadas no desenvolvimento de todo o processo educativo" (artigo 22 ${ }^{\circ}$, parágrafo $1^{\circ}$ ). Segundo este mesmo documento legal, a escola bilíngue deve estar disponível aos alunos surdos desde a educação infantil, se estendendo aos primeiros anos do ensino fundamental, o que significa muito mais do que matriculá-los no ensino regular. ${ }^{17}$

Ainda conforme as determinaçóes do Decreto n. 5.626/2005, nos anos seguintes do ensino fundamental (a partir do $6^{\circ}$ ano), ensino médio e ensino superior abre-se também a possibilidade de inserçáo do aluno surdo em salas de aula comuns do ensino regular. Porém, destaca-se que esses momentos da escolarização devem continuar acontecendo a partir de uma perspectiva bilíngue. ${ }^{18}$

Enfim, a inclusão de surdos no ensino regular parece ser um desafio constante, pois uma educação com qualidade para esses alunos perpassa por questôes que vão além da matrícula dos mesmos nessa modalidade de atendimento. Significa, neste momento histórico, um repensar sobre a proposta inclusiva, a partir das referências bilíngues de ensino, para entâo, efetivamente, construir uma educaçáo que atenda aos anseios dos surdos brasileiros.

\section{Referências}

BRASIL. Lei n. 10.436, de 24 de abril de 2002. Dispóe sobre a Língua brasileira de sinais - Libras e dá outras providências. Disponível em: <http://portal.mec.gov.br/seesp/>. Acesso em: dez. 2011.

BRASIL. Decreto n. 5.626, de 22 de dezembro de 2005. Regulamenta a Lei n. 10.436, de 24 de abril de 2002 e o artigo 18 da Lei n. 10.098, de 19 de dezembro de 1994. Disponível em: <http://portal.mec.gov.br/ seesp/>. Acesso em: dez. 2011.

BRASIL. Secretaria de Educação Especial. Política Nacional de Educaçáo Especial na perspectiva da Educaçáo Inclusiva. Brasília: MEC, 2008. Disponível em: <http://portal.mec.gov.br/seesp/>. Acesso em: dez. 2011.

BRASIL. Microdados do Censo Escolar 2007: manual do usuário. Brasília, DF: MEC/INEP, março de 2009.

BRASIL. Censo Escolar: educacenso. Caderno de Instruçóes. Brasília, DF: MEC/INEP, jun. 2010.

BRASIL. Microdados do Censo Escolar 2009: manual do usuário. Brasília, DF: MEC/INEP, mar. 2010.

CARVALHO, R. E. Diferença, deficiência e necessidades educacionais especiais. In: CARVALHO, R. E. Temas em Educaçáo Especial. Rio de Janeiro: WVA, 1998, p. 101-113.

FERREIRA, M. C. C.; FERREIRA, J. R. Sobre inclusão, políticas públicas e práticas pedagógicas. In: GÓES, M. C. R.; LAPLANE, A. L. F. (Orgs.). Políticas e práticas de educaçáo inclusiva. Campinas: Autores Associados, 2004, p. 21-48. (Coleçẫo Educação Contemporânea).

HÖFLING, E. M. Estado e políticas (públicas) sociais. Cadernos Cedes: Políticas Públicas e Educação. Campinas: CEDES, v. 21, n. 55, nov., p. 30-41, 2001.

KASSAR, M. C. M. Matrículas de crianças com necessidades educacionais especiais na rede de ensino regular: do que e de quem se fala? In: GÓES, M. C. R.; LAPLANE, A. L. F. (Orgs.). Políticas e práticas de educaçáo inclusiva. Campinas: Autores Associados, 2004, p. 49-68. (Coleção Educação Contemporânea).

LACERDA, C. B. F. Um pouco da história das diferentes abordagens na educação dos surdos. Cadernos Cedes: A nova LDB e as necessidades educativas especiais. Campinas: Cedes, n. 46, p. 68-80, 1998.

LODI, A. C. B.; LACERDA, C. B. F. (Orgs.). Uma escola, duas línguas: letramento em língua portuguesa e língua de sinais nas etapas iniciais da escolarizaçáo. Porto Alegre: Mediação, 2009, 160 p.

LANCILLOTTI, S. S. P. Deficiência e trabalho: redimensionando o singular no contexto universal. Campinas: Autores Associados, 2003. (Coleçấo Polêmicas do Nosso Tempo), 111 p.

MENDES, E. G. A radicalização do debate sobre inclusão escolar no Brasil. Revista Brasileira de Educaçáo. v. 11, n. 33, set./dez, p. 387-405, 2006. 


\section{Notas}

${ }^{1}$ Ano em que se publicou no país a nova Política Nacional de Educação Especial na perspectiva da Educação Inclusiva. Porém, é importante esclarecer que o movimento em prol da educação inclusiva é anterior a esta data e por não ser objeto deste estudo optou-se por não aprofundar esta discussáo.

${ }^{2}$ Sabe-se que a opção terminológica é um diferencial importante que revela posicionamentos éticos e políticos. Considerando que importa para este estudo a diferenciação entre surdez e deficiência auditiva e náo as várias possibilidades terminológicas para designar a pessoa com surdez, informa-se que neste texto utiliza-se o termo surdo e pessoa surda ou com surdez como sinônimos.

${ }^{3}$ As concepçóes constantes no Caderno de Instruçôes do INEP sobre este público-alvo (alunos com deficiência, transtornos globais do desenvolvimento e altas habilidades/superdotação) estão em consonância com as concepçóes do público-alvo de alunos da Educaçáo Especial apresentado na Política Nacional de Educaçáo Especial na perspectiva da Educaçấo Inclusiva, de 2008. Apesar da Política não diferenciar os termos surdez e deficiência auditiva esses dois grupos de alunos são compreendidos como deficientes sensoriais. A mesma forma de entendimento está empreendida no Caderno de Instruçóes do INEP: surdez e deficiência auditiva fazem parte do grupo de alunos com deficiência, entendidos por este Instituto como "aqueles que têm impedimentos de longo prazo de natureza física, intelectual, mental ou sensorial, os quais, em interação com diversas barreiras, podem obstruir sua participação plena e efetiva na sociedade em igualdade de condiçóes com as demais pessoas" (BRASIL, 2010, p. 33).

${ }^{4}$ Essas três modalidades são as únicas apontadas pelo INEP para o preenchimento dos dados. No Caderno de Instruçóes disponibilizado para as escolas consta a seguinte definição para cada modalidade de atendimento: "ensino regular: oferece educação infantil, ensino fundamental, ensino médio e educação profissional; educação especial: atende exclusivamente alunos com deficiência, transtorno global do desenvolvimento ou altas habilidades/superdotaçáo, ou conta com classes especiais para esses alunos nas etapas da educaçâo básica; educaçáo de jovens e adultos: destinada àqueles que não tiveram acesso ou continuidade de estudos no ensino fundamental e médio em idade própria” (BRASIL, 2010, p. 16).

${ }_{5}^{5}$ Sabe-se que o conceito de necessidades educacionais especiais tem sido amplamente discutido na atualidade no campo da educaçáo especial, especialmente por ser um conceito muito amplo que abarca diversas possibilidades e diferenciados perfis de alunos. Alguns autores, como Carvalho (1998), sugerem que as necessidades educacionais especiais não estấo no indivíduo, mas sim na relaçấo deste com o ambiente. Nesse sentido, muitos alunos, com diferentes obstáculos em seu processo de ensino e aprendizagem, podem apresentar, temporariamente ou permanentemente, necessidades educacionais especiais. Não é intençáo deste estudo problematizar de forma aprofundada esta questâo, apesar de considerá-la importante. Acredita-se ser relevante evidenciar como o INEP entende este conceito. O Manual do Usuário utilizado pelas escolas no momento do preenchimento dos dados do censo escolar, que demonstra cada passo do preenchimento, não traz uma definição clara sobre o termo necessidades educacionais especiais. Porém, o Instituto o compreende como sinônimo de alunos com deficiências, transtornos globais do desenvolvimento e altas habilidades/ superdotação, pois, ao dividir os alunos por "categorias", como por exemplo "alunos com surdez", utiliza-se o termo "tipo de necessidade educacional especial".

${ }^{6}$ Decreto que regulamenta a Lei n. 10.436, de 2002, que reconhece a Língua Brasileira de Sinais (Libras) no país.

${ }^{7}$ Esclarece-se que, nos microdados do INEP, constam as informaçóes por tipo de necessidade educacional especial. Assim, optou-se, neste gráfico e nos dois seguintes, por demonstrar os dados relacionados ao grupo de surdos e deficientes auditivos separados a fim de compará-los. Optou-se, também, por evidenciar a soma desses dois grupos (que foi realizada pela própria pesquisadora) para facilitar a visualização dos dados em relação ao número total de alunos com necessidades educacionais especiais, isto é, alunos que possuem cegueira, baixa visão, surdez, deficiência auditiva, surdocegueira, deficiência física, deficiência mental, transtornos globais do desenvolvimento (que nos microdados de 2007 e 2008 constam como um único grupo e nos microdados de 2009 e 2010 são subdivididos em autismo clássico, síndrome de asperger, síndrome de rett e psicose infantil), síndrome de down (que consta apenas nos microdados de 2007 e 2008), deficiência múltipla e altas habilidades/superdotaçáo.

${ }^{8}$ Observa-se que apenas em 2009 chega-se a $11 \%$.

${ }^{9}$ Ressalta-se que Mato Grosso do Sul concentra, em média, 20\% dos alunos surdos e deficientes auditivos da regiāo Centro-Oeste.

${ }^{10}$ Dito em outras palavras, o que se quer instigar à reflexão é: se a concepção de surdez e deficiência auditiva do INEP não está em consonância com as políticas públicas atuais no campo da educaçăo de surdos, especialmente o Decreto n. 5.626/2005, qual o entendimento que chega ao universo particular da escola, ou ainda, estará claro para a pessoa responsável pelo preenchimento do censo escolar a diferenciação entre esses dois grupos de alunos?

${ }^{11}$ Conforme orientação do INEP para o preenchimento do censo escolar, modalidade refere-se ao "modo, maneira ou metodologia de oferecer o ensino" (BRASIL, 2010, p. 85). 
${ }^{12}$ Esclarece-se que, nesta tabela, bem como nas tabelas 02 e 03 , optou-se por evidenciar apenas as informaçóes relacionadas às modalidades de atendimento de surdos e deficientes auditivos, visando uma aproximação maior do objeto de estudo.

${ }^{13}$ Confira os gráficos 01, 02 e 03.

${ }^{14} \mathrm{O}$ objetivo deste estudo năo é aprofundar as "questôes de fundo" do movimento inclusivo no Brasil como, por exemplo, o fato da educação inclusiva não se direcionar apenas aos alunos considerados público-alvo da educação especial. Porém, não se pode desconsiderar o impacto desta proposta no âmbito da educação dos dois grupos de alunos que são foco desta pesquisa - surdos e deficientes auditivos.

${ }^{15}$ Nesse caso, a inclusão pode ser entendida como um movimento compensatório, que não discute as questốes relacionadas à exclusão.

${ }^{16}$ Está se referindo ao modelo de acesso ao ensino regular com os serviços da educação especial disponíveis. No caso da surdez, na maioria das vezes, oferece-se apenas do tradutor e intérprete de Libras, sendo que a proposta bilíngue de ensino contempla diversos outros serviços, como o instrutor de Libras, por exemplo. Para saber mais a respeito confira Lodi e Lacerda (2009).

${ }^{17}$ De acordo com Lacerda (1998), o objetivo da educação bilíngue é que a criança surda possa ter um desenvolvimento cognitivo-linguistico equivalente ao verificado na criança ouvinte.

${ }^{18} \mathrm{Ou}$ seja, o professor regente precisa estar sensível às singularidades linguísticas desse aluno e o mesmo deve ser assistido, além do tradutor e intérprete de Libras/Língua Portuguesa, por um professor para o ensino de Língua Portuguesa como segunda língua para pessoas surdas.

\section{Correspondência}

Raquel Elizabeth Saes Quiles - Universidade Federal de Mato Grosso do Sul, Centro de Ciências Humanas e Sociais. Fundação Universidade Federal de Mato Grosso do Sul. CEP: 79070-900 - Campo Grande, Mato Grosso do Sul - Brasil.

E-mail: rquiles@bol.com.br

Recebido em 25 de fevereiro de 2014

Aprovado em 12 de setembro de 2014 
